\title{
Systèmes d'alimentation durables basés sur les ressources fourragères locales
}

\author{
B Peyre de Fabrègues, G Forgiarini
}

\author{
CIRAD EMVT B.P 5075 Montpellier, France
}

Dans la région du Lac de R'Kiz (province du Trarza, sud ouest de la Mauritanie), l'élevage est prépondérant avec des systèmes d'exploitation des ressources fourragères basés sur l'utilisation successive de deux types de ressources:

- les pâturages naturels du domaine dunaire,

- les surfaces fourragères pâturées, naturelles ou non, du domaine dépressionnaire.

Ces pâturages ont été au centre du «Programme de développement intégré de la Grande Région de R'Kiz" confiée en 19931995 au CIRAD-EMVT et au CIRAD-Forêts. Leur production et les modes d'exploitation (élevages transhumants ou sédentaires, production de lait ou de viande, incidence du foncier) ont été étudiés.

La cartographie des ensembles pastoraux a été réalisée au $1 / 100000^{e}$ pour une «aire de référence de 500000 ha" centrée sur R'Kiz (domaine dunaire) et au $1 / 25000^{\circ}$ pour les dépressions submersibles du Lac de R'Kiz proprement dit (domaine dépressionnaire).

- Pâturages natureis du domaine dunaire.

II s'agit de végétation principalement herbacée annuelle très dépendante des pluies estivales (juin-septembre) qui se dessèchent sur pieds, à partir de septembre. La valeur nutritive est bonne aux premiers stades (début des pluies, jusqu'à la montaison), acceptable en vert, et de moins en moins bonne après dessiccation. Une complémentation est alors nécessaire soit à l'aide de ligneux quand ils sont verts, soit à l'aide de sous produits dont le principal est le tourteau d'arachide provenant du Sénégal, et qui est réservé aux vaches laitières.
- Productions fourragères du domaine dépressionnaire.

Il s'agit pour l'essentiel de végétaux spontanés poussant après décrue dans les dépressions (nombreuses et vastes) inondables par la crue du Sénégal (avec ou sans contrôle). Leur intérêt vient surtout de leur entrée en production - et en accessibilité en raison du retrait de l'eau - en saison sèche, après épuisement des pâturages dunaires dont ils assurent le relais et aussi de leur très importantes productivité (les bourgoutières peuvent produire de 15 à 20 tonnes de matière sèche par ha, alors que le système dunaire ne dépasse guère en moyenne 1,5 t/ha les meilleures années) en même temps que d'une bonne valeur nutritive observée sur ces végétaux hydrophiles (cas des bourgoutières et du riz sauvage).

- Le système est caractérisé par sa bipolarité qui constitue une forme naturelle de "complémentarité fourragère». La contrainte d'accessibilité liée aux inondations est déterminante pour la durabilité dans des systèmes d'élevage où l'effectif du troupeau importe plus que sa production. Cette contrainte ne suffit pas toutefois à éviter les excès de surpâturage, et une adaptation de la pression pastorale serait souhaitable.

Il faut donc réglementer le calendrier fourrager et en même temps informer de façon accessible les éleveurs sur l'intérêt d'un emploi rationnel des sous produits complémentaires en particulier en leur donnant les moyens de déterminer et de cibler les animaux qui valorisent le mieux ces intrants. 